\title{
EVALUATING THE EFFECTIVENESS OF ENVIRONMENTAL PROTECTION EFFORTS ON INCREASING THE CONVERGENCE BETWEEN THE EU AND ROMANIA - RETHINKING THE COMMON PROBLEMS
}

\author{
Jean Vasile Andrei ${ }^{1}$, Rodica-Manuela Gogonea ${ }^{2}$, Aurelia Patrascu ${ }^{3}$, Marian Zaharia ${ }^{4}$ \\ *Corresponding author E-mail: manuela.gogonea@gmail.com
}

\begin{abstract}
A R T I C LE IN F O
Original Article

Received: 11 May 2019

Accepted: 25 May 2019

doi:10.5937/ekoPolj1902389A

UDC 502:323.21(498:4-672EU)

Keywords:

convergence, environmental protection, energy consumption, investments, clusters analysis

JEL: H23; O44; P48; Q5.

A B S T R A C T

The main aims of the paper are to asses and evaluate the effectiveness of environmental economics efforts on increasing the convergence between the EU and Romania in terms of environmental protection, from an economic perspective, using a cluster analysis applied for all the EU28 Member States (MS). In the paper are constructed seven clusters considering five determinant and topic related variables by using Hierarchical Clustering methodology, starting from the hypothesis of identifying presumptive environmental economic patterns among all the EU-28 countries. The results obtained during the research confirm the existence of determinant and significant elements that shapes a proactive environmental protection policy by grouping the MS in appropriate clusters. The paper suggested also that, despite of important financial efforts related to environmental protection and resilience, there is still a small impact on GDP growth.
\end{abstract}

(C) 2019 EA. All rights reserved.

\section{Introduction}

Sustainable development is based on an effective environment policy that ensures optimal interaction between the economy and the environment. Specifically, the socioeconomic development should be in a permanent process of continuity, provided it does

1 Jean Vasile Andrei, Assoc.prof.habil., Petroleum - Gas University of Ploiesti, Faculty of Economic Sciences, B-dul, Bucuresti, No.39, 100680, Ploiesti, Prahova, Romania, E-mail: andrei_jeanvasile@yahoo.com, ORCID ID: https:///orcid.org/0000-0002-8332-6537

2 Rodica-Manuela Gogonea, Assoc.prof, The Bucharest University of Economic Studies, 15-17 Dorobanti St., Sector 1, 010552 Bucharest, Romania, E-mail: manuela.gogonea@gmail.com

3 Aurelia Patrascu, Assoc.prof., Dean of the Faculty of Economic Sciences, Petroleum -Gas University of Ploiesti, B-dul Bucuresti, No.39, 100680, Ploiesti, Prahova, Romania, E-mail:patrascuaura@yahoo.com

4 Marian Zaharia, full professor, Faculty of Economic Sciences, Petroleum -Gas University of Ploiesti, B-dul Bucuresti, No.39, 100680, Ploiesti, Prahova, Romania, E-mail: marianzaharia53@gmail.com

http://ea.bg.ac.rs 
not affect the environment, and it protects the natural resources necessary for human existence. As in literature (Clark, J. (2017), Panayotou, T. (2016) and Sachs, W. (2015), in contemporary and well functional economies environmental protection represents not only a major objective as political, societal and academic approach, but also it reunites the efforts in promoting economic resilience. Despite numerous technological changes, massive investments, and the new European environmental paradigm developments, environmental protection continues to be one of the most un-convergent policies and imposes numerous debates.

Staring from the assumption that an effort to promote and acquire a functional and active environmental protection implies both specific and complementary instruments and financial allotments both form the national and companies' budgets, the environmental protection efforts cause significant challenges, which need to be well oriented and evaluated as it is highlighted in (Hardisty, P.(2010), Choi, S., \& Ng, A.(2011), Goodland, R.(1995), Spangenberg, J. H. (2005) and Labuschagne, C., Brent, A. C., \& Van Erck, R. P. (2005).

Taking into account that the GDP is the most important indicator of economic growth (Huang, B. N., Hwang, M. J., \& Yang, C. W. (2008), Costanza, R., Hart, M., Talberth, J., \& Posner, S. (2009), Zilio, M., \& Recalde, M. (2011), the changes analyzed for environmental protection expenditures as \% in GDP (EPE) and total environmental investments as \% in GDP (TEI) are the most significant.

Although the European Union has an environment strategy based on synergy, there are differences in the applicability of environmental policy regulations between constituent countries, a situation proven also by the analysis of the three indicators (ELP, EPE and TEI) for 23 EU countries.

According to Eurostat, (2017), the process of analyzing the percentage value fluctuations for both the environmental protection expenditures as \% in GDP and for total environmental investments as \% in GDP showed that in 2011, compared to 2002, six countries are experiencing a reduction: Luxembourg, Austria, Germany, Hungary, Portugal, and Slovenia. The growth trend of both indicators is registered for Estonia, UK, Sweden, Poland, Latvia, Romania, Croatia, Lithuania, and the Netherlands.

Taking into account the data available at the beginning of the research, the paper was mainly focused on the period 2002-2011 and on 23 out of 28 EU Member States. In the first part of the research we analyzed the evolution of the three indicators both at the EU level and for the 23 states included in the research.

The main objective of this paper is to identify and highlight the quantitative and qualitative aspects of EU Member States' policies on their spending and investment in environmental protection. Three indicators were used for this end: environmental protection expenditure as \% in GDP (EPE), shares of environmental and labour taxes in total tax revenues from taxes and social contributions (ELP) and total environmental investments as \% in GDP (TEI). On the other hand we try to identify the characteristics 
of the evolution of the three indicators, and the extent to which quantitative assessments are statistically significant at the level of each country. From this perspective, the main research instrument used in carrying out the analysis on this paper was the Hierarchical Clustering methodology, which is employed to determine economic behavioral models among the EU-28 Member States in terms of environmental protection efforts, and to review the influence of the five (5) considered variables (environmental protection expenditure, greenhouse gas emissions, intensity of energy consumption, environmental investments, primary energy consumption and environmental and labour taxes) on designing the environmental protection behavior at the EU-28 level.

The second part of the research is a cluster analysis through which the groups have been formed and their main characteristics have been statistically determined and tested. In order to highlight the mutations determined by the economic evolutions and policies of the analyzed states for the cluster analysis, we chose years 2002 and 2011 (beginning and end of the analyzed period).

\section{Research methodology}

In this study the research methodology employed for achieving the main objectives is based on previous works in the field, improved and adapted to the specific goals followed as in (Gelder, 2014; Andrei et al., (2016), Zaharia and Gogonea, (2016); Jugănaru and Jugănaru, (2016), Rotaru T. (ed.), Badescu G., Culic I., Mezei E. \& Murean C. ( 2006)

In order to achieve the objective of the first part of the research, the following matrix was developed:

$$
\boldsymbol{X}=\left\|\boldsymbol{x}_{i j k}\right\|_{i=\overline{1,3} \boldsymbol{j}=\overline{1 p}, t=\overline{1, m}}
$$

In (1), $\mathrm{i}=1$ corresponds to the EPE variable, $\mathrm{i}=2$ corresponds to the ELP variable, and $\mathrm{i}=3$ corresponds to the TEI variable. Starting from the matrix $\mathrm{X}$, for the $\mathrm{p}$ countries and the three indicators, the averages of the analyzed period and the matrix of the coefficients of variation (V) are determined (Rotariu, 2006):

$$
V=\left\|\frac{s_{j}}{\bar{x}_{j}}\right\|_{i=\overline{1,3 j}=\overline{1 p}}, s_{j}^{2}=\frac{\sum_{t=1}^{m}\left(x_{i j t}-\bar{x}_{j}\right)^{2}}{m-1}, \bar{x}_{j}=\frac{\sum_{t=1}^{m} x_{i j t}}{m} .
$$

Taking into account the values of the $\mathrm{V}$ matrix, we identified - for each one of the three indicators - the countries for which they provide a good characterization of the evolution during the analyzed period ( ), and the countries for which the indicators do not provide acceptable information.

Also, confidence intervals for the average values have been determined and tested statistically. The condition for accepting the assumption of the null hypothesis ( $\mathrm{H}_{-} 1$ : 
the average is not statistically significant), is that the confidence interval ( ) limits would have different signs.

$$
\Delta \bar{x}_{i j}=\bar{x}_{j} \pm \text { Std.err }{ }_{j} \cdot t_{\frac{\alpha}{2}, m-1}, \quad S t d . e r r=\sqrt{\frac{s_{j}^{2}}{m}}
$$

For a better picture of the evolution of the three indicators in the analyzed countries, the values of linear regression coefficients were determined, using ANOVA. Testing their statistical significance was done with the $t$ (student) test. The condition of accepting the null hypothesis (H0_2: the value of the regression coefficient is not statistically significant) is:

$$
-\boldsymbol{t}_{\frac{\alpha}{2}, \boldsymbol{m}-2}<\frac{\hat{\boldsymbol{b}}_{\boldsymbol{j}}}{\boldsymbol{s}_{\hat{\boldsymbol{b}}_{i j}}}<\boldsymbol{t}_{\frac{\alpha}{2}, \boldsymbol{m}-2}, \quad \boldsymbol{s}_{\hat{\boldsymbol{b}}_{\boldsymbol{j}}}=\frac{\sum_{t=1}^{m}\left(\boldsymbol{x}_{\boldsymbol{i j t}}-\hat{\boldsymbol{x}}_{\boldsymbol{i} \boldsymbol{j} t}\right)^{2}}{\boldsymbol{m}-2} / \frac{1}{\sum_{t=1}^{m}(t-\bar{t})^{2}} .
$$

In the second part of the research two clusters analyses were carried out, the first one corresponding to the year 2002, and the second one corresponding to the year 2011. The analysis started from the matrices:

$$
\boldsymbol{Y}_{2002}=\left\|\boldsymbol{y}_{2002 \boldsymbol{j}}\right\|_{i=\overline{1,3} \boldsymbol{j}=\overline{1} \boldsymbol{p}}, \quad \boldsymbol{Y}_{2011}=\left\|\boldsymbol{y}_{2011 \boldsymbol{j}}\right\|_{i=3 \boldsymbol{j}=\overline{1} \boldsymbol{p}}
$$

On the matrix elements Y2002 and Y2011 the following transformation was applied (Zaharia et al., 2017):

$$
z_{i j}=\frac{y_{j}-\bar{y}_{i}}{\sigma_{i}}, \text { where } \bar{y}_{i}=\frac{\sum_{j=1}^{p} y_{j}}{n}, \quad \sigma_{i}=\sqrt{\frac{\sum_{j=1}^{p}\left(y_{j}-\bar{y}_{i}\right)^{2}}{p-1}} \text {. }
$$

Proximity Matrix was obtained using Euclidian distance (Rotariu, 2006; Zaharia et al., 2017):

$$
W=\left\|w_{j}\right\|_{j=1 \bar{p}, l=1, p}, \quad w_{j}=\sqrt{\sum_{j=1}^{p}\left(z_{l}-z_{j}\right)^{2}}, i=\overline{1,3}, l=\overline{1, p}, j \neq i, k \neq i, w_{i}=0
$$

and for the distance between clusters, we used the Average Linkage method. For the testing of the significance of the variables belonging to clusters, we used ANOVA, the null hypothesis H0 (cluster belonging of the analyzed variable is not statistically significant) being given by (Zaharia et al., 2017):

$$
F_{\text {stat }}=\frac{\sum_{i=1}^{r}\left(\bar{y}_{i}-\bar{y}_{0}\right)^{2} n_{i} / \boldsymbol{f}_{1}}{\sum_{i=1}^{r} \sum_{j=1}^{\dot{n}}\left(y_{j}-\bar{y}_{i}\right)^{2} / \boldsymbol{f}_{2}}<F_{\alpha, r-1, n-r} \quad \text { equivalent o } \quad \text { Sig } F>\alpha
$$

Significance level used was 95\%. To generate the clusters and test the statistical hypothesis, the SPSS package was used. The method was chosen based on the premise that it has a high degree of applicability and it can be used in order to design significant groups in terms of indicator significance and displays. 


\section{Results and discussions}

At the level of the European Union, between 2002 and 2011, the environmental protection expenditure as \% in GDP (EPE), the share of environmental and labour taxes in total tax revenues from taxes and social contributions (ELP), and total environmental investments as \% in GDP (TEI) had significantly different evolutions (Figures 1a, 2a, 3a).

Figure 1. Evolution of the value (a) and of the area of the value (b) of environmental protection expenditure as \% in GDP (EPE), at European Union level in 2002-2011.

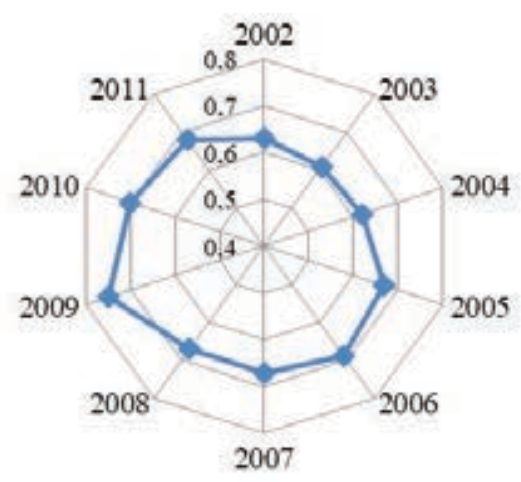

(a)

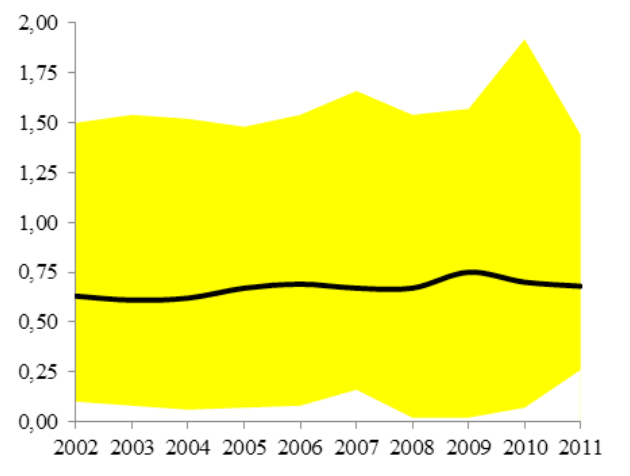

(b)

Source: authors based on EUROSTAT (2017)

While the shares of environmental and labour taxes in total tax revenues from taxes and social contributions recorded maximum values (over 6.5\%) between 2002 and 2005, and minimum values (6.03\%) in 2008 and (6.37\%) in 2011, the environmental protection expenditure as \% in GDP reached the maximum values (over 0.7\%) in 20092010 , and the minimum values $(0.62 \%)$ in the period 2002-2004. Compared to 2002 , ELP decreased in 2011 by $6.59 \%$ while EPE increased by $7.94 \%$.

Figure 2. The evolution of the value (a) and of the area of the value (b) of total environmental investments as \% in GDP (TEI), at European Union level in 2002-2011

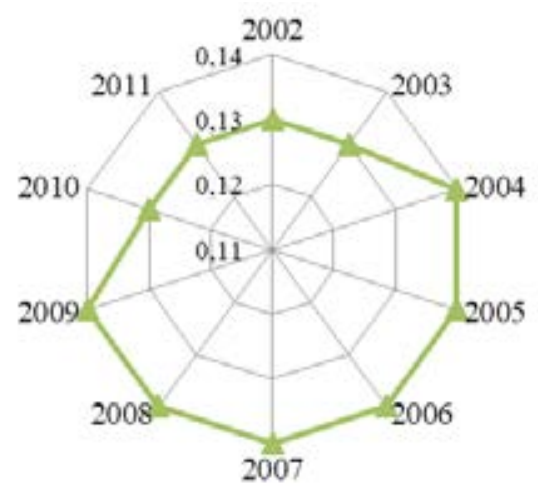

(a)

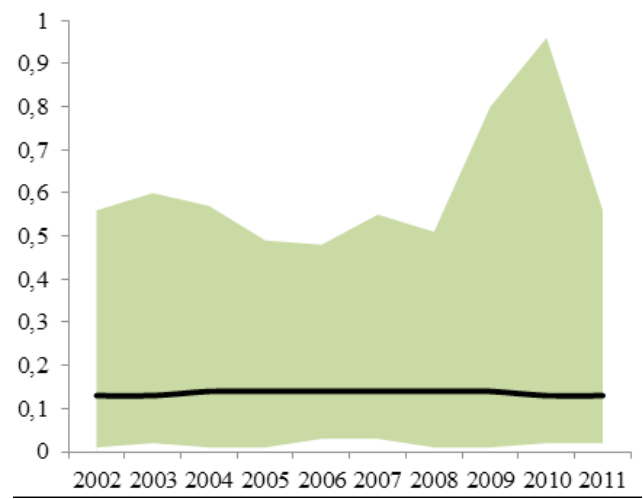

(b) 
As regards total environmental investments as \% of GDP, it recorded peak values in the period before the economic crisis, and even in its first year, namely in 2004-2009. Starting with 2010 , the TEI decreased from $0.14 \%$ to $0.13 \%$, reaching in 2010 the level it had reached in 2002.

Figure 3. - The evolution of the value (a) and of the area of the value (b) of shares of environmental and labour taxes in total tax revenues from taxes and social contributions (ELP), at European Union level in the period 2002-2011

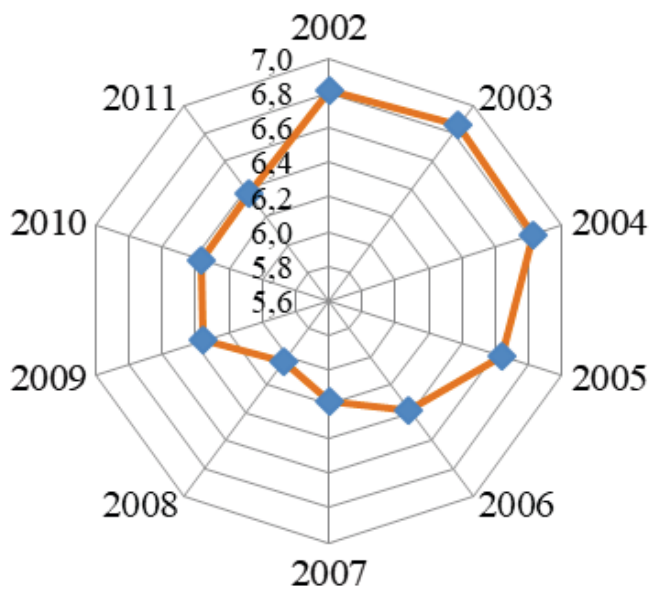

(a)

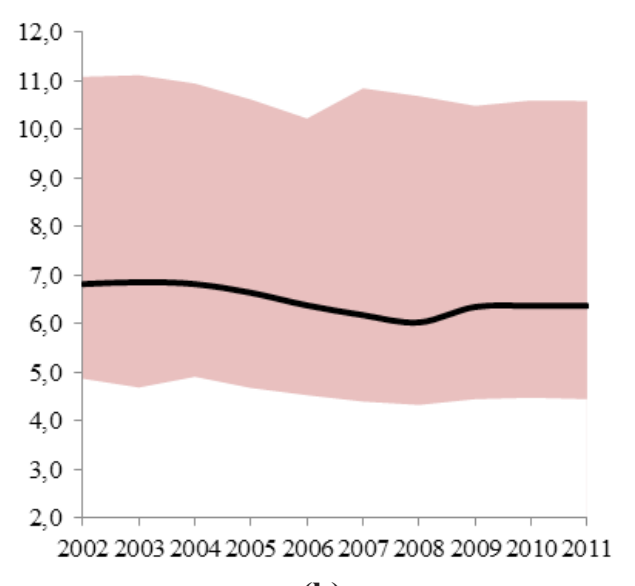

(b)

Source: authors based on EUROSTAT (2017)

These values characterize the European Union at a global level. They are annual average values and may hide contradictory developments at Member State level. In order to identify how the values recorded in the analyzed period of the three indicators at the level of each Member State we determined, in a first phase, the average values and the corresponding coefficients of variation.

The economic and social phenomena, as well as the conditions and policies adopted in the Member States, led to different evolutions of the three indicators, with changes in the variation ranges being more or less compact (Figure 1b, 2b, 3b). The narrowest of these and relatively convergent is the area of the values of the shares environmental and labour taxes in total tax revenues from taxes and social contributions. By contrast, the evolution of environmental protection as $\%$ in GDP and total environmental investments as $\%$ in GDP indicates a great diversity, mainly after the economic crisis.

The fact that the trajectories of the average values of the three indicators are in the first third of the evolution areas shows that in a significant proportion of the countries included in the analysis the evolutions of ELE, ELP and TEI were not affected by major disturbances.

At the level of the analyzed countries, the average environmental protection expenditure as $\%$ in GDP ranged between $0.13 \%$, in Croatia, and $1.5 \%$ in the Netherlands. Value differences between countries can be explained based on the differences in the economic 
structure (different proportions of the sectors of activity: industry, agriculture, services).

Of the 23 countries included in the analysis, for 95\% confidence level, in eight countries (Belgium, Bulgaria, Latvia, Lithuania, Poland, Romania, Slovakia and United Kingdom) there was an increasing trend of environmental protection expenditure as \% in GDP. In addition to this, for $90 \%$ confidence level, there is France and Malta. Of these, the most significant increase in environmental protection expenditure as \% in GDP was recorded in Lithuania, with an annual growth of 0.129 percentage points, followed by Romania, with an annual increase of 0.088 percentage points.

On the other hand, for 95\% confidence level, there have been decreasing trends in environmental protection expenditure as \% of GDP in five countries (Germany, Luxembourg, Hungary, Austria and Slovenia). Of these, significant annual reductions in the values of this indicator were recorded in Hungary ( -0.047 percentage points), Austria (-0.036 percentage points) and Slovenia (-0.032 percentage points). In the other eight countries (Estonia, Spain, Croatia, Italy, Netherlands, Portugal, Finland and Sweden), oscillating developments were recorded around the mean values, the highest value of the standard deviation of 0.1177 being registered in Italy. For these countries the values of the regression coefficients are not statistically significant for either $95 \%$ or $90 \%$ confidence level, assuming the null hypothesis (H0_2).

In the case of the EPL - the shares of environmental and labour taxes in total tax revenues from taxes and social contributions, the average values were between 4.58 (France) and 10.18 (Croatia). For 90\% confidence level, the EPL registered an upward trend only in the Netherlands (with an annual growth of 0.023 percentage points) and Poland (with an annual increase of 0.026 percentage points). For $95 \%$ confidence level, the EPL recorded a decreasing trend in Italy, Malta, Hungary, Slovakia, Finland, and Sweden. Please note that for the other 15 countries, oscillating developments were recorded around the mean value, which means that the regression coefficient values are not statistically significant for either $95 \%$ or $90 \%$ confidence level, assuming the null hypothesis (H0_2).

For the third TEI indicator - total environmental investments at the level of the analyzed countries, the average values as \% in GDP ranged between $0.03 \%$ in Sweden and $0.46 \%$ in Slovenia. In the analyzed period, 14 countries (Bulgaria, Estonia, Croatia, Italy, Latvia, Luxembourg, Malta, Netherlands, Austria, Poland, Romania, Finland, Sweden, and UK) had a growing trend for $95 \%$ confidence level. For the other 9 countries there were oscillating developments recorded around the mean values, with the highest value of standard deviation (0.3014) being registered in Lithuania. For these states, the values of the regression coefficients are not statistically significant for either $95 \%$ or $90 \%$ confidence level, assuming the null hypothesis (H0_2).

Given the evolution of the values of the three analyzed indicators (EPE, ELP and TEI), the 23 countries were grouped using the hierarchical cluster method while performing a comparative analysis of these groups in the years 2002 and 2011 to highlight the quantitative and qualitative differences for each cluster. 
Choice regarding the number of clusters is based on the significant reduction of the Total Sum of Squared Error (Peeples, Matthew A., 2011) on the one hand, and on a better readability of the results, on the other hand. Under these circumstances, seven clusters resulted. The Fisher test (Table 1) highlights the fact that all three variables included in the analysis are significant in terms of cluster membership.

Table 1. Results of testing the hypothesis regarding the belonging of the variables EPE, ELP and TEI to clusters, using ANOVA

\begin{tabular}{|l|c|c|c|c|c|c|}
\hline & \multirow{2}{*}{$\mathrm{df} 1$} & \multirow{2}{*}{ df 2} & \multirow{2}{*}{$\mathrm{F}_{0.05 ; 4 ; 4}$} & \multicolumn{2}{|c|}{ Fstat } & \multirow{2}{*}{ Sig.F } \\
\cline { 5 - 6 } & & & 2002 & 2011 & \\
\hline EPE & 6 & 16 & 2.74 & 21.189 & 18.819 & .000 \\
\hline ELT & 6 & 16 & 2.74 & 9.757 & 11.791 & .000 \\
\hline TEI & 6 & 16 & 2.74 & 20.047 & 24.393 & .000 \\
\hline
\end{tabular}

Source: Authors' own computations

For the first year of the analyzed period, the grouping by clusters of the 23 analyzed countries, as well as their ranking according to GDP per capita, is shown in Figure 4.

Figure 4 - Grouping of countries by clusters according to the value of environmental protection expenditure as \% in GDP (EPE), of the shares of environmental and labour taxes in total tax revenues from taxes and social contributions (EPL) and, of total environmental investments as \% in GDP, in 2002. Source: authors based on EUROSTAT (2017)

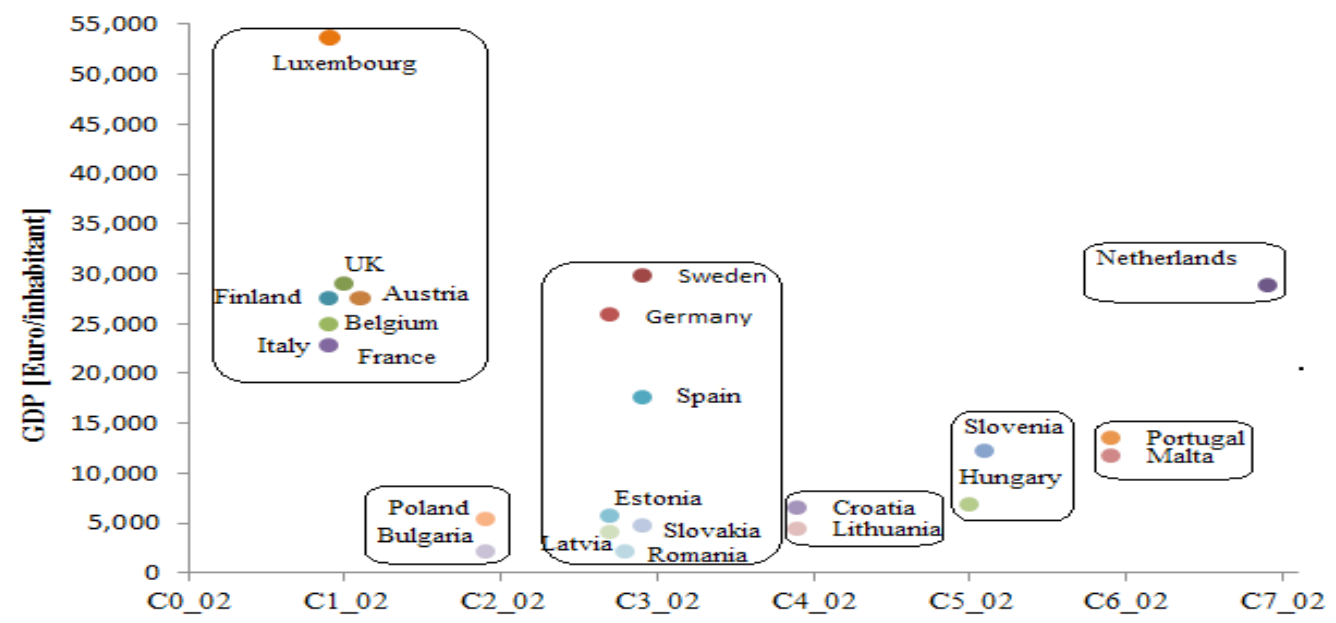

Depending on the average values of the EPE, ELP, TEI variables recorded at cluster level the spatial distribution of clusters centers is shown in Figure 5. 
Figure 5 The spatial distribution of clusters centers at the 2002 level.

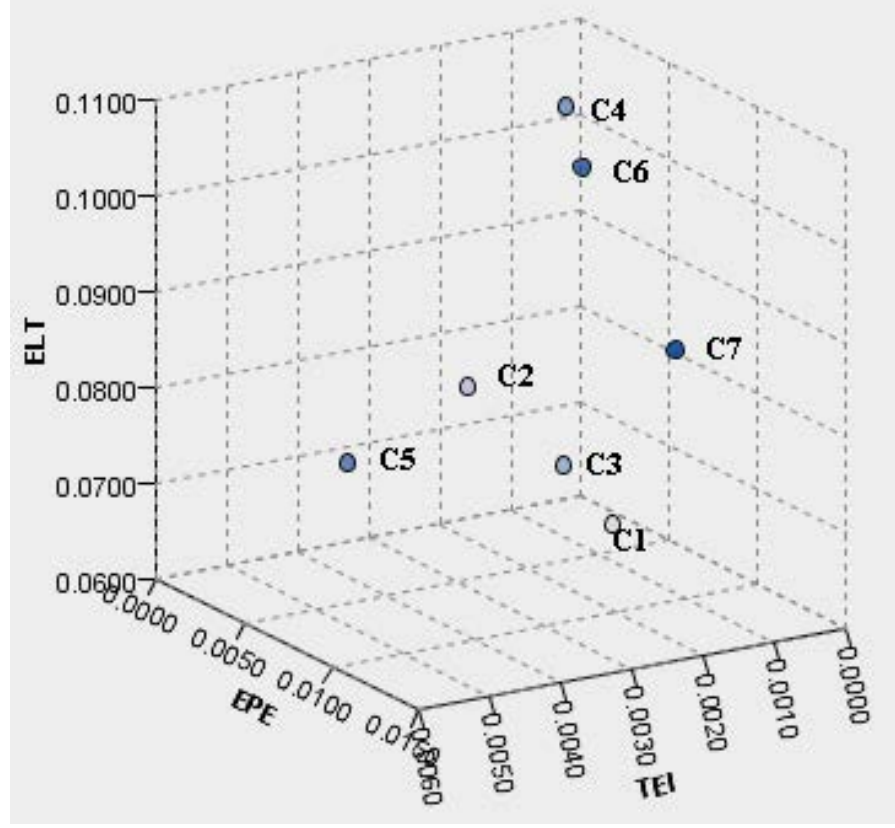

Source: authors ' based on EUROSTAT (2017)

The most countries are concentrated in Cluster 1 (Belgium, France, Italy, Luxembourg, Austria, Finland, UK) and in Cluster three (Germany, Spain, Latvia, Romania, Slovakia, Sweden). In addition, four clusters include only two countries: C2 with Bulgaria and Poland, C4 with Croatia and Lithuania, C5 with Hungary, Slovenia, and C6 with Malta and Portugal. As far as the Netherlands is concerned, by the values of the average indicators analyzed, it is situated in a cluster by itself $(\mathrm{C} 7)$. The territorial representation of the results is shown in Figure 6. 
Figure 6. Territorial distribution of the clusters based on the values of environmental protection expenditures as \% in GDP (EPE), of the shares of environmental and labour taxes in total tax revenues from taxes and social contributions (EPL), and of total environmental investments as \% in GDP, recorded in 2002.

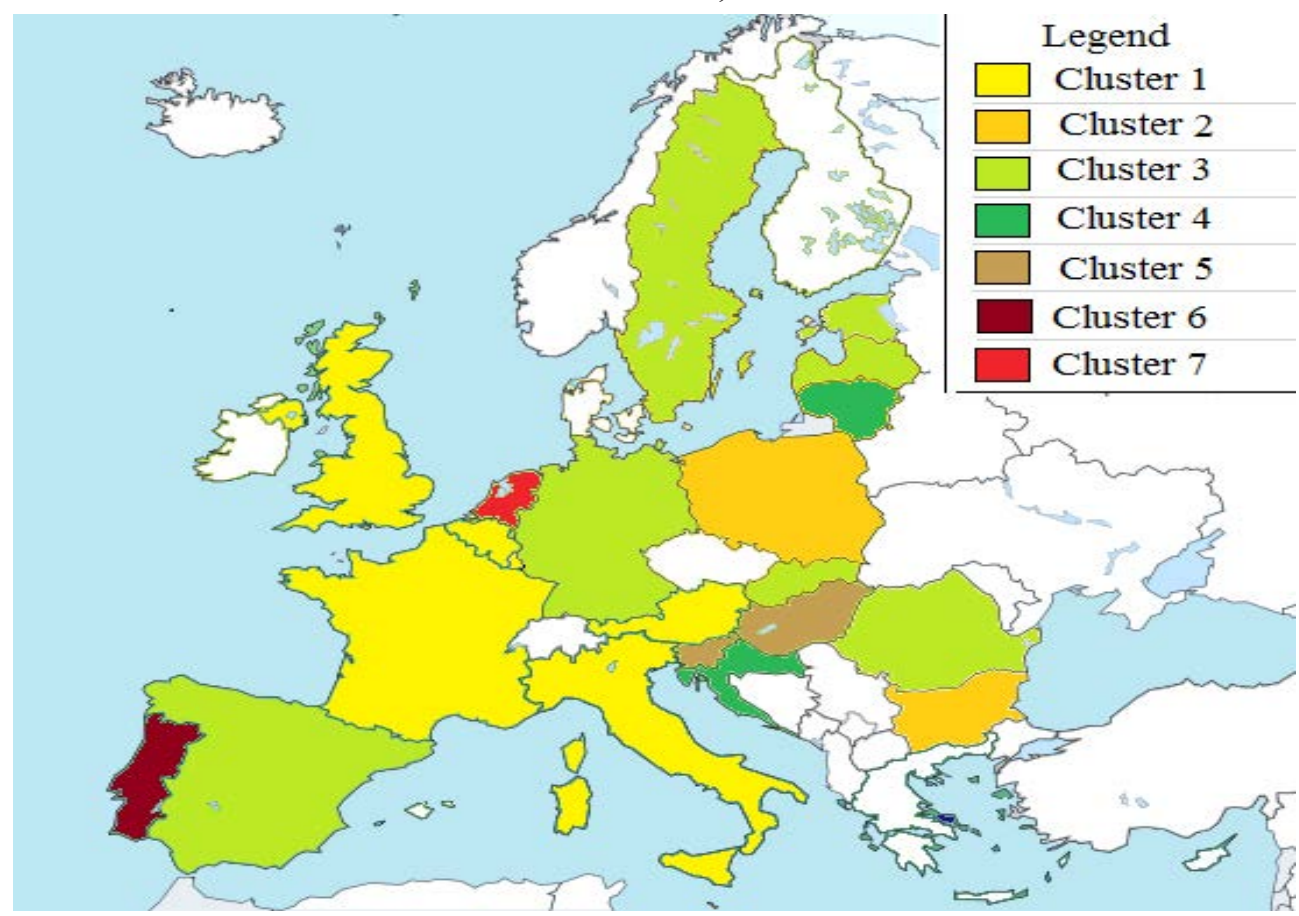

Source: authors based on EUROSTAT (2017)

At the end of the analyzed period, due to the economic evolutions and the peculiarities of the countries included in the analysis, the values of the three indicators underwent changes (presented in the first part of the article) which led to a reorganization of the clusters in 2011 compared to 2002 (Figure 7). 
Figure 7 - Country grouping by clusters, according to the value of environmental protection expenditures as \% in GDP (EPE), of the share of environmental and labour taxes in total tax revenues from taxes and social contributions (EPL), and of total environmental investments as $\%$ in GDP, in 2011

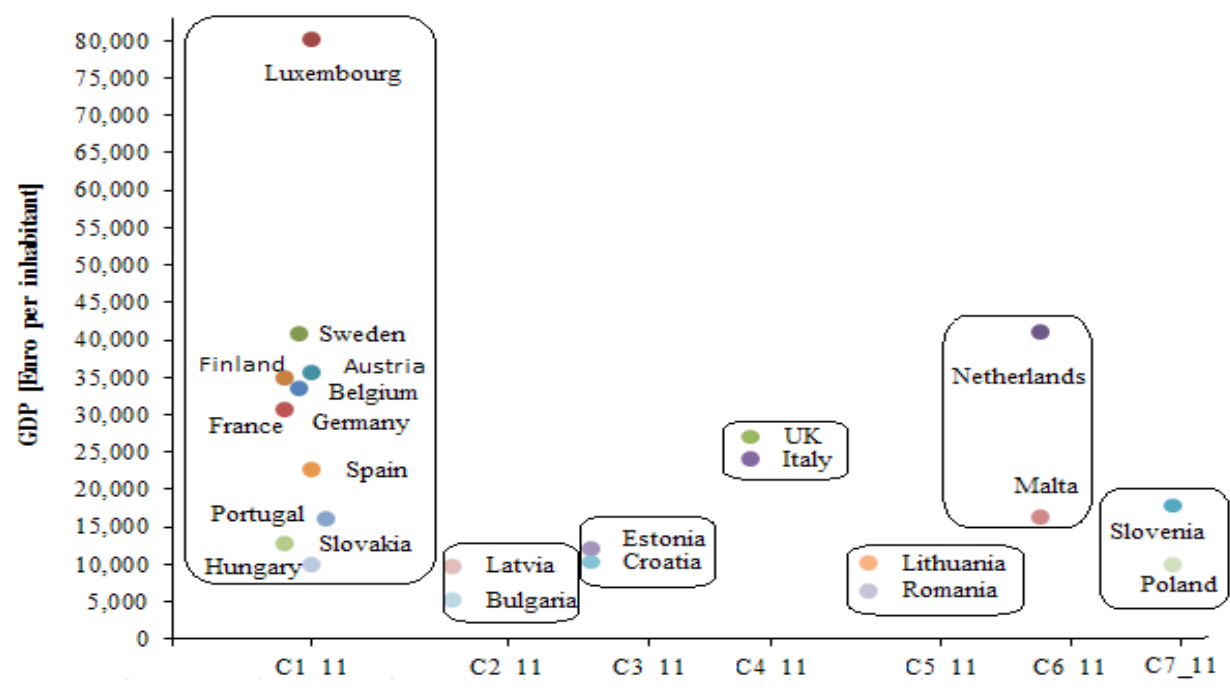

Source: authors based on EUROSTAT (2017)

At the 2011 level, the spatial distribution of clusters centres is shown in Figure 8.

Figure 8 The spatial distribution of clusters centers at the 2011 level.

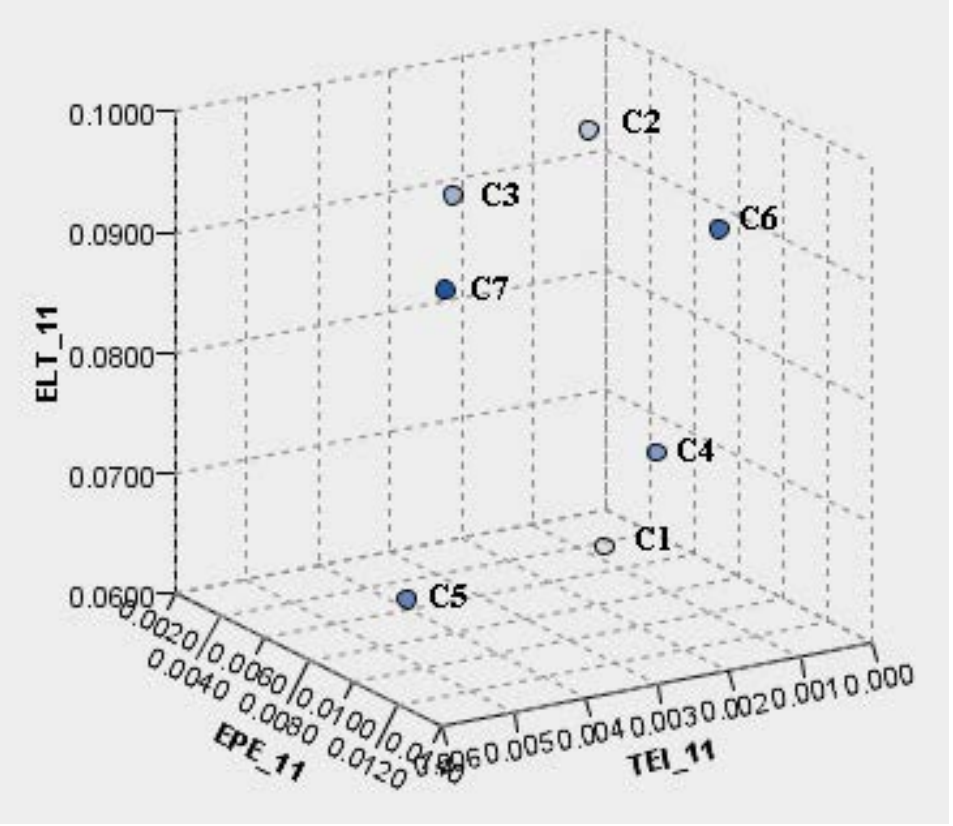

Source: authors based on EUROSTAT (2017) 
The most significant cluster remains the first - C1 - with a concentration of 11 countries: Belgium, Germany, Spain, France, Luxembourg, Hungary, Sweden, Finland, Austria, Portugal, and Slovakia. All the other six clusters consist of two countries: C2 with Bulgaria and Latvia, C3 with Estonia and Croatia, C4 with Italy and UK, C5 includes Lithuania and Romania, C6 with Malta and Netherlands and C7 with Poland and Slovenia.

Figure 9 shows clearly the territorial distribution of these clusters, according to the values of environmental protection expenditures as \% in GDP (EPE), of the share of environmental and labour taxes in total tax revenues from taxes and social contributions (EPL), and of total environmental investments as \% in GDP

Figure 9- Territorial distribution of clusters based on values of environmental protection expenditure as \% in GDP (EPE), of the shares of environmental and labour taxes in total tax revenues from taxes and social contributions (EPL) and, of total environmental investments as $\%$ in GDP, registered in 2011

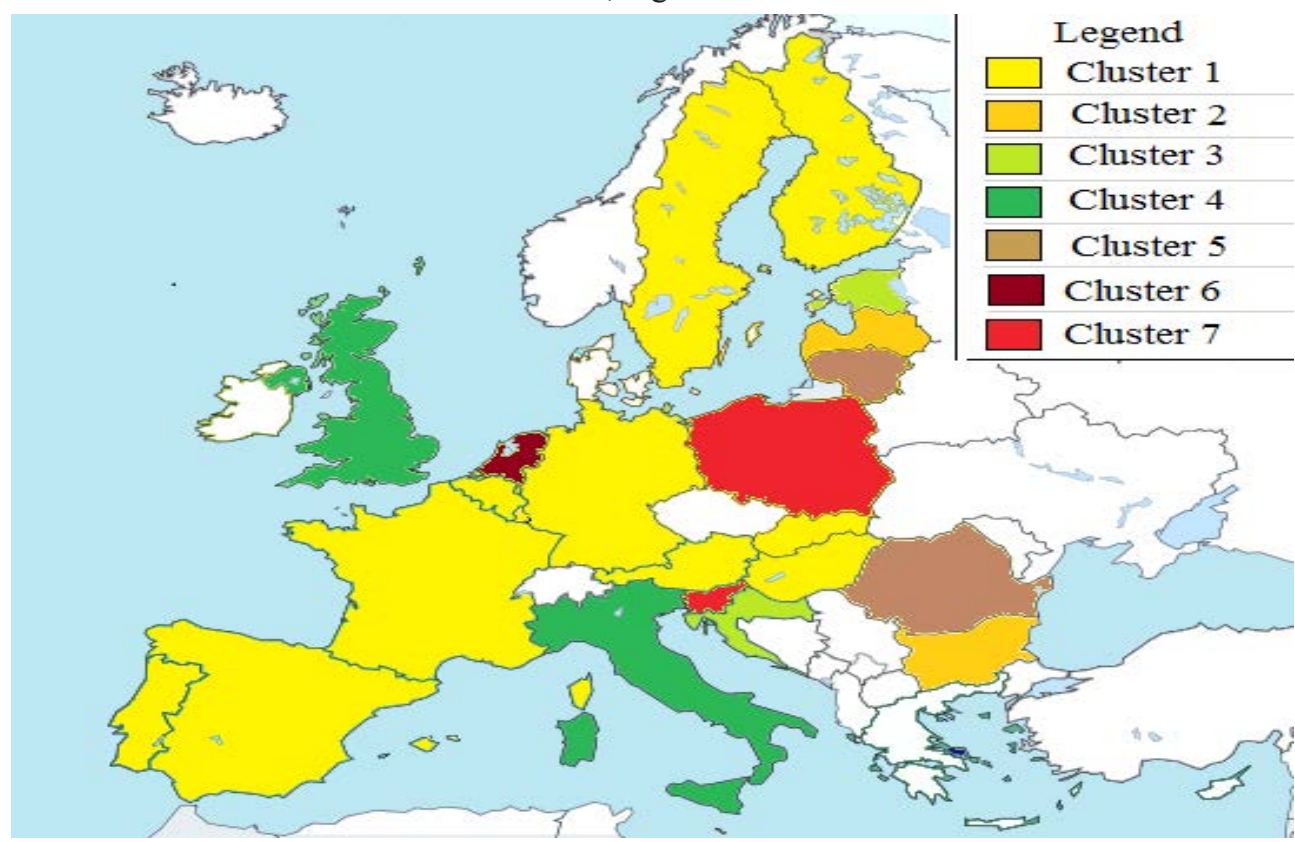

. Source: authors based on EUROSTAT (2017)

Each cluster indicates a specific political behavior with major influences on spending and investment in environmental protection. Thus, a profile of the countries in the seven clusters can be achieved, according to the environmental policy undertaken by governments in relation to the three indicators analyzed: EPE, ELP, and TEI.

As in Figure 5, the clusters obtained do not have the same composition in the two analyzed years. Belgium, France, Luxembourg, Finland, Austria are countries with similarities in terms of the indicators analyzed, which are in the same cluster (C1) both in 2002 and in 2011.Bulgaria, Estonia and Malta are countries that have retained 
their cluster in both analyzed years. Portugal and Hungary are characterized by value oscillations of the indicators that favored switching from one cluster to another in 2011 compared to 2002 .

In 2002, values in the Netherlands are significantly different from the other countries analyzed, and required a separate analysis of this country in terms of policy in the light of the three indicators. Concerning the composition of the clusters, the most significant changes in the number of countries are reported for the first and third clusters. The average percentage values determined by clusters of the indicator shares of environmental and labour taxes in total tax revenues from taxes and social contributions (ELP) are between $6.49 \%$ (2002) and 6.03\% (2011) for cluster 1 and a maximum of $10.33 \%$ for cluster 6 in 2002, respectively $9.75 \%$ for cluster 2 in 2011 (Figure 10).

Figure 10 - Country grouping according to the average values of environmental and labour taxes in total tax revenues from taxes and social contributions

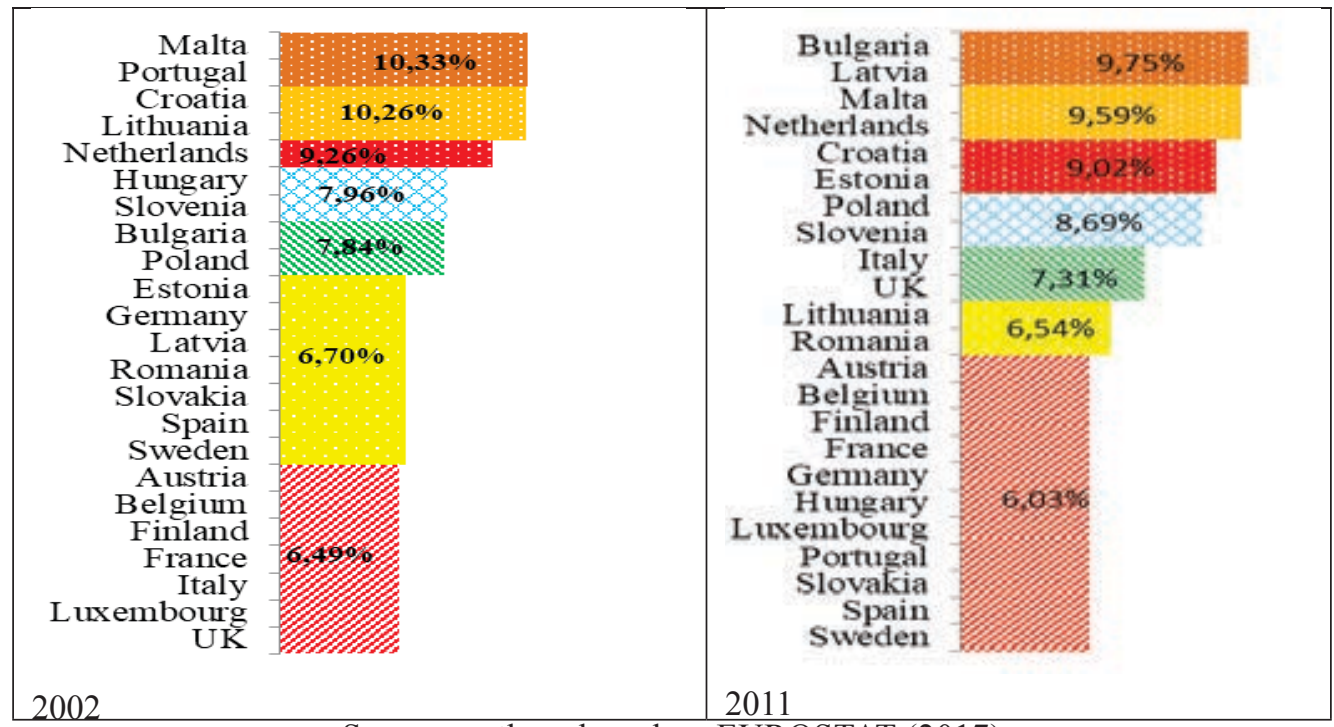

Source: authors based on EUROSTAT (2017)

The indicator shares of environmental and labour taxes in total tax revenues from taxes and social contributions corresponding to clusters over the two analyzed years highlights the changes in terms of structure and value. Significant decreases are recorded for C4 $(-2.96 \%)$ and C5 $(-1.42 \%)$ and less significant for C6 $(-0.74 \%)$, C $7(-0.57 \%)$ and C1 $(-0.46 \%)$. Increases are recorded at C3 $(+2.31 \%)$ and C2 $(+1.91 \%)$.

The evolution of the average percentages of the shares of environmental and labour taxes in total tax revenues from taxes and social contributions by clusters, according to figure 10, is the result of changes in the percentage values of the variable, by countries. Thus, significant for the analysis are the changes recorded by the countries that remain in the same cluster. The justification takes into account the fact that the cluster represents a level of hierarchy which allows for a clearer comparison of the analyzed variable in 2011 compared to 2002. 
Belgium, France, Luxembourg, Austria, Finland (countries belonging to the EU-15 subgroup) are in C1 both in 2002 and 2011, indicating relatively close concerns and results in terms of the applied policy on the share of environmental and labour taxes in total tax revenues from taxes and social contributions. Of the five countries, Finland is the only country where we see a $4.51 \%$ increase in shares of environmental and labour taxes in total tax revenues from taxes and social contributions. For other countries, there are decreases: in Luxembourg ELT decreased by $9.92 \%$, France by $8.62 \%$, Austria by $4.21 \%$ and Belgium by only $2.46 \%$.

Bulgaria, part of C2 for both years of analysis, has a $28.99 \%$ growth rate in shares of environmental and labour taxes in total tax revenues from taxes and social contributions in 2011 compared to 2002, thus landing the second place after Estonia (part of C3) with the highest growth rate $(35.58 \%)$.

Maintained on the same level of clustering for both years of analysis, Malta, part of C6, is facing a fairly significant reduction process in the shares of environmental and labour taxes in total tax revenues from taxes and social contributions, namely $14.07 \%$ in 2011 compared to 2002 .

Italy and the UK, part of C1 in 2002, which re-entered C4 in 2011, are down by $0.5 \%$ and $6.93 \%$ in the shares of environmental and labour taxes in total tax revenues from taxes and social contributions in 2011 compared to 2002. In 2011, in C1, six other countries joined the five countries that have maintained their position: Germany, Spain, Hungary, Sweden, Portugal, Slovakia, the decreases determined for shares of environmental and labour taxes in total tax revenues from taxes and social contributions being between a minimum rate of $2.18 \%$ (Hungary) and a maximum of $25.18 \%$ (Portugal, which holds the penultimate position in terms of reduced decrease of the ELT).

In 2002 Bulgaria joins Poland at a 6.57\% growth rate, and Latvia in 2011, for which the share of growth of environmental and labour taxes in total tax revenues from taxes and social contributions in 2011 compared to 2002 is by $15.58 \%$.

Shares of environmental and labour taxes in total tax revenue from taxes and social contributions for Romania, part of C3 in 2002 and C5 in 2011, decreased by $8.75 \%$ in 2011 compared to 2002 . A decrease by $13.47 \%$ is recorded by Croatia (part of C_02 and C3_11) for shares of environmental and labour taxes in total tax revenues from taxes and social contributions in 2011 compared to 2002.

The largest decrease, by $35.95 \%$, of shares of environmental and labour taxes in total tax revenue from taxes and social contributions in 2011 compared to 2002, was registered by Lithuania, which in 2002 was part of C4, and in 2011 it was a component of the C5 cluster. Also in C5, but in 2002, Slovenia corresponds to an increase of ELT by $9.78 \%$ in 2011 compared to 2002.

Netherlands was part of the last cluster in 2002 (C7) and the penultimate cluster (C6) in 2011 , registering an increase by $4.10 \%$ in the share of environmental and labour taxes in total tax revenue from taxes and social contributions in 2011 compared to 2002. 
The process of analysing this indicator (shares of environmental and labour taxes in total tax revenues from taxes and social contributions) reflected the oscillations, in the form of relative increases or decreases, recorded by countries that remain in the same cluster, or changing their clusters in 2011 compared to 2002, being a consequence of the environmental strategies applied by their governments. Other fluctuating trends in the policy outcomes applied by the governments of the 23 EU countries for environmental protection are also highlighted by the environmental protection expenditure as $\%$ in GDP (EPE) indicator.

Compared with the shares of environmental and labour taxes in total tax revenues from taxes and social contributions, much lower percentage values for the 23 EU countries are recorded for environmental protection expenditure as \% in GDP.

The average percentage values split by clusters of the indicator environmental protection expenditures as \% in GDP are between minimum $0.11 \%$ (2002) corresponding to cluster 4, respectively $0.32 \%$ (2011) for cluster 3 , and a maximum of $1.50 \%$ (in 2002 corresponding to cluster 7), respectively 1.32\% (in 2011, in cluster 6), as shown in Figure 11.

The country grouping according to the average values of the environmental protection expenditures as \% in GDP highlights for most clusters increases: in C4 by $0.80 \%$, in C6 by $0.63 \%$, in C2 by $0.28 \%$, in C 5 by $0.06 \%$, and in C3 by $0.05 \%$. These increases are also reflected in an increase of $0.11 \%$ in 2011 compared to 2002, recorded for environmental protection expenditure as \% of GDP in all EU countries included in the analysis. For clusters $\mathrm{C} 1$ and $\mathrm{C} 7$, the decreases are quite insignificant, by only $0.21 \%$, respectively by $0.84 \%$.

Figure 11 - Country grouping according to average values of environmental protection expenditures as \% in GDP recorded at cluster level.

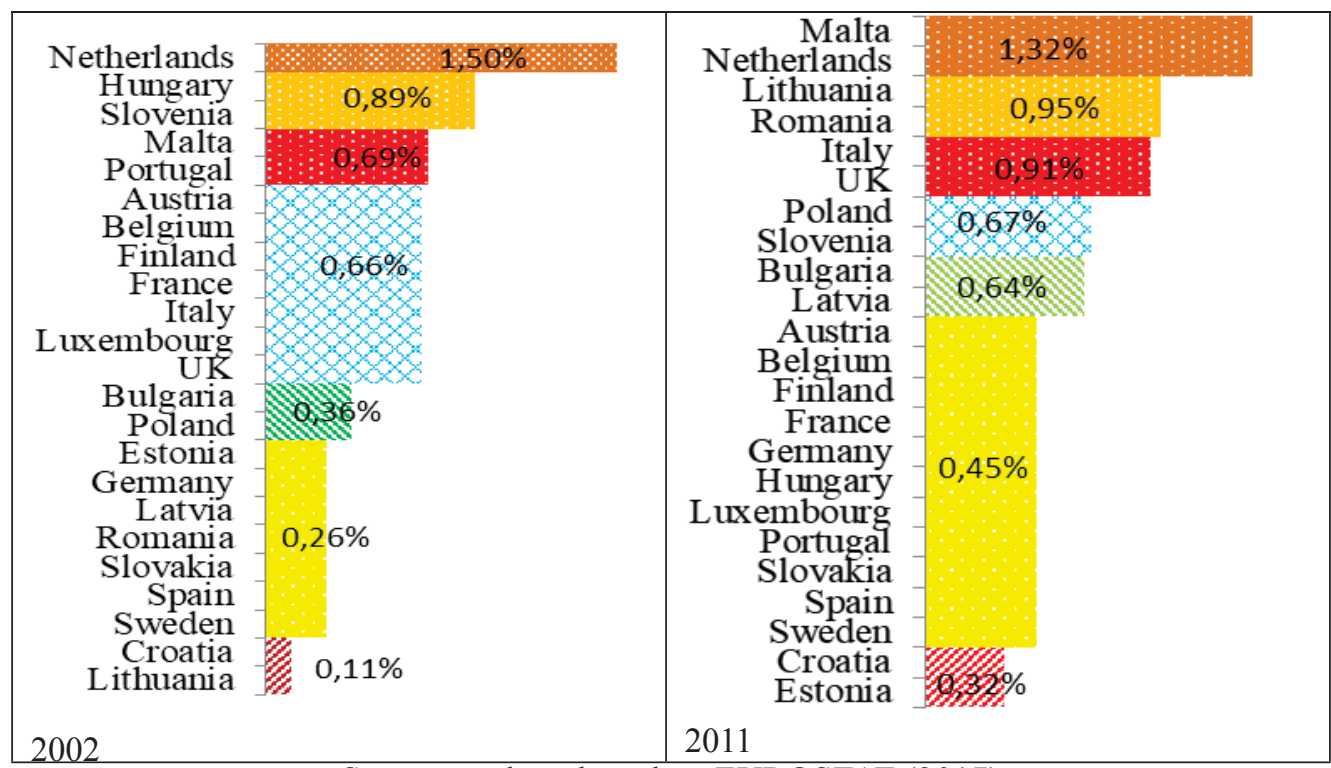

Source: authors based on EUROSTAT (2017) 
The study of changes in environmental protection expenditures as \% in GDP per country, concerns mainly countries that are in the same cluster both in 2011 and in 2002. These countries have paces of change of EPE in different ways. Thus, for Belgium and Finland, environmental protection expenditures as \% of GDP saw an increase by $20.69 \%$ and $3.51 \%$ in GDP, while Luxembourg and Austria faced a significant reduction of the indicator by $28.38 \%$ and $45.45 \%$ in GDP. France is the country to which corresponds the same percentage of $0.58 \%$ of EPE in GDP.

As with the previous indicator, Bulgaria $(\mathrm{C} 2)$ shows an increase in environmental protection expenditure as \% in GDP in 2011 compared to 2002 with $71.43 \%$ in GDP, as does Estonia, whose growth rate is $6.90 \%$ in GDP.

If for the previous indicator Malta (C6) recorded a decrease in 2011 compared to 2002, this time, for environmental protection expenditure as \% of GDP, an increase of $39.53 \%$ in GDP was determined. The percentage value of $0.88 \%$ of the environmental protection expenditure as\% of GDP for Italy is the same in 2002 and 2011. For the UK, environmental protection expenditure as \% of GDP increases in 2011 compared to 2002 by $93.75 \%$ in GDP.

Spain, Sweden, Slovakia are three countries in C1_2011 for which EPE increased in 2011 compared to 2002 by $4.00 \%$, by $3.13 \%$ and respectively $63.16 \%$ in GDP.

The evolution of the indicator environmental protection expenditure as \% in GDP, as in the case of the indicator shares of environmental and labour taxes in total tax revenues from taxes and social contributions for other three countries in C1_2011 (Germany, Hungary, Portugal), is still decreasing. Decreases are by $21.43 \%$ in GDP for Germany, $45.07 \%$ in GDP in Hungary, and only $7.69 \%$ in GDP in Portugal.

Poland, a C2 component in 2002, recorded, just like the shares of environmental and labour taxes in total tax revenues from taxes and social contributions, a growth rate of the environmental protection expenditure as \% in GDP but by $43.24 \%$.

The most significant growth rates of environmental protection expenditure as $\%$ in GDP are determined for Romania (375.00\% in GDP), part of C3_2002 and C5_2011, then for Latvia (277.78 \% in GDP) belonging to C2 cluster, by $166.67 \%$ In GDP for Croatia, part of C4_2002 and C3_2011.

If for shares of environmental and labour taxes in total tax revenues from taxes and social contributions, the highest decrease was recorded for Lithuania, in the case of environmental protection expenditure as $\%$ in GDP, for this country was calculated the highest GDP growth (840.00\%).

Environmental protection expenditures as \% in GDP recorded in 2011, compared to 2002 , a decline by $24.53 \%$ in GDP for Slovenia, and by $4.00 \%$ in GDP for the Netherlands. The analysis of the indicator environmental protection expenditure as $\%$ in GDP included the interpretation of the results obtained as a result of the clustering of the countries in 2002 and 2011. The determined average values allowed reflecting the 
changes registered by the 23 EU member states in 2011 compared to 2002 by relatively oscillating ratios from country to country, and implicitly from one cluster to another.

In this context, the environmental protection analysis continued with the indicator: total environmental investments as \% of GDP (TEI). This is another indicator with a significant impact on environmental protection, recording, as the environmental protection expenditure as \% in GDP, low percentage values for all 23 countries included in the analysis.

Compared with the above-mentioned indicator (environmental protection expenditure as $\%$ in GDP), the average percentage values determined by clusters are significantly higher (Figure 12). Thus, the calculated percentage averages are situated in 2002 between a minimum for $\mathrm{C} 4$ by $0.05 \%$ in GDP and a maximum for C5 of $0.55 \%$ in GDP. In 2011, the average values of the total environmental investments as $\%$ in GDP range from $0.08 \%$ in GDP for C1 to $0.51 \%$ in 2011 in GDP for C5.

Figure 12 - Country grouping according to average values of the environmental protection expenditure as \% in GDP

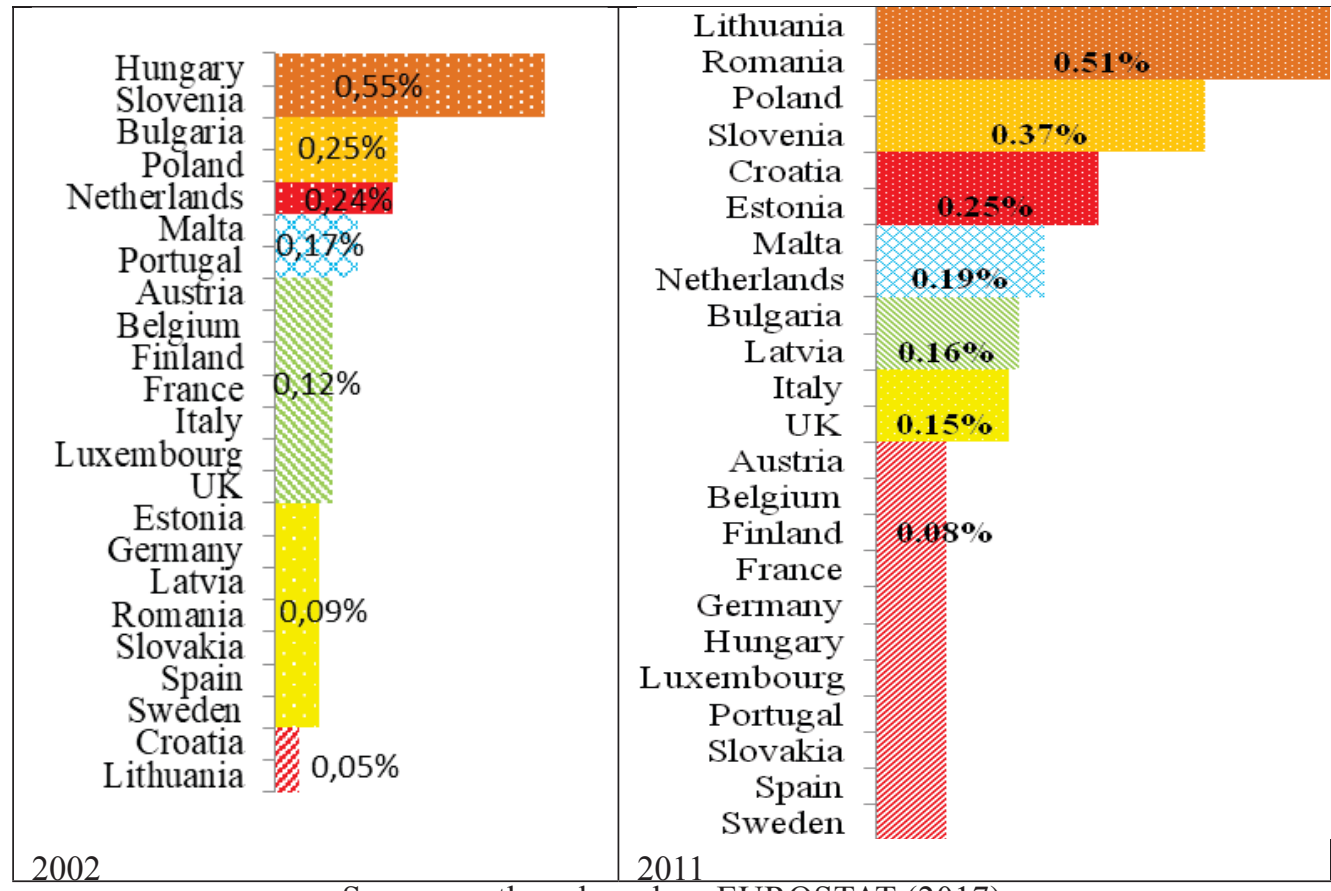

Source: authors based on EUROSTAT (2017)

Compared to the environmental protection expenditure as $\%$ of GDP, the third indicator included in the analysis (total environmental investments as \% in GDP) also records an upward trend. The growth trend is lower by $0.02 \%$ in 2011 compared to 2002 . The same trends were seen in the majority of clusters for total environmental investments as $\%$ of GDP decrease as those for environmental protection expenditures as $\%$ in GDP. Thus, C3, C7, C4 and C6 recorded increases in 2011 compared to 2002 by $0.16 \%, 0.13 \%$, 
$0.10 \%$ and $0.03 \%$. The most significant is for the total environmental investments as $\%$ in GDP, cluster two (C2) by $0.10 \%$ compared to $\mathrm{C} 5$ and $\mathrm{C} 1$, which had reductions in 2011 compared to 2002 by only $0.05 \%$ and $0.04 \%$.

For all five countries of C1_2002 and C1_2011 there is a process of reducing the total environmental investments as \% in GDP in 2011 as compared to 2002. The most significant decrease is recorded in Belgium, with 78.95\% in GDP, followed by Austria with $33.33 \%$ in GDP, France by $27.27 \%$ in GDP, Finland by $14.29 \%$ in GDP and Luxembourg by $5.00 \%$ in GDP.

Bulgaria, the common component of C2 for 2002 and 2011, recorded the same percentage of $0.19 \%$ in GDP. Estonia, component of C3 in 2002 and 2011, also shows a growth process, as in the case of the other two indicators analyzed, and thus, in 2011, the total environmental investments as \% in GDP was increased by $84.62 \%$ higher compares with 2002.

The same decreasing oscillation as with the other two variables is also recorded for Malta. A state belonging to C6, both in 2002 and 2011, recorded a decrease of the total environmental investments as $\%$ in GDP by $25.00 \%$ in GDP.

The trend of keeping constant the percentage of total environmental investments as $\%$ in GDP is noticed; just as the environmental protection expenditure as \% in GDP for Italy, but the percentage is lower, being placed at $0.18 \%$ in GDP.

In the UK, the growth in 2011 compared to 2002 of the percentage of total environmental investments as \% in GDP is very high (300\%) compared to the one of the previously analyzed indicator (EPE).

For cluster C1_2011, Sweden has an increase in total environmental investments as \% in GDP by $100 \%$ in GDP in 2011 compared to 2002, while the other five countries are seeing decreases, as follows: Hungary with $75.00 \%$ in GDP, Portugal with $64.71 \%$ In GDP, Slovakia with $46.15 \%$ in GDP, Germany with $33.33 \%$ in GDP, and Spain with $30.77 \%$ in GDP.

In C2_2002 Poland is included besides Bulgaria, a country for which the total environmental investments as \% increased by $22.58 \%$ in GDP. At the same time, in the same cluster, but for the next year of analysis (C2_2011), Latvia appears together with Bulgaria, Latvia, also with an increase of total environmental investments as \% in GDP (as for the other indicators), of only $33.33 \%$ in GDP.

As with environmental protection expenditure as \% in GDP, Romania, part of C3_2002 and C5_2011, recorded a growth process. However, this upward trend at the level of total environmental investments as \% in GDP is excessive, with 1400\% in GDP being mentioned (the first in the ranking of the 23 countries included in the analysis). A significant increase for total environmental investments as \% in GDP is reported in 2011 as compared to 2002, and for Croatia, with a percentage of 550\% in GDP.

Given that even in the case of environmental protection expenditure as \% in GDP, 
Lithuania is experiencing the highest growth. Even for total environmental investments as $\%$ in GDP, it can be mentioned that a similar situation appears for total environmental investments as \% in GDP. Significantly higher growth $(833.33 \%)$ of total environmental investments as \% of GDP places this country on the second place as a growth pace among all 23 countries surveyed.

Slovenia, part of C5_2002 and C7_2011, saw a reduction in total environmental investments as \% in GDP by 35.19\% in GDP, in 2011 compared to 2002.

Component of C7_2002 and C6_2011, the Netherlands recorded an increase just like in the case of the shares of environmental and labour taxes in total tax revenues from taxes and social contributions, with $8.33 \%$ in 2011 compared to 2002.

Sweden is the country with the lowest percentages for total environmental investments as \% in GDP both in 2002 and 2011. The highest percentage value $(0.56 \%)$ was registered by Hungary in 2002 and by Lithuania in 2011.

The analysis of the evolution of the indicator total environmental investments as \% in GDP by country and cluster was mainly highlighted by the growth or decrease rates calculated for each country. This reflected as well the country-specific changes within the same cluster or from one cluster to another, in 2011 compared to 2002.

In 2002 - 2011, all the value oscillations recorded by the three indicators (the environmental protection expenditure as \% in GDP, the shares of environmental and labour taxes in total tax revenues from taxes and social contributions and total environmental investments as \% in GDP), have resulted in significantly different changes in each country and, implicitly, from one cluster to another. These are the result of environmental policies that have been outlined and applied since the world economic crisis in 2008, in country, but also through the cohesion manifested within the European Union.

\section{Conclusions}

The analysis carried out in this paper aimed at creating an overall picture of the environmental protection efforts following the environmental policies established and adopted after the 2008 economic crisis. This aspect was highlighted as a result of the data collection from 2002 and 2011, for 23 EU countries, in terms of environmental protection expenditure as \% of GDP (EPE), shares of environmental and labour taxes in total tax revenues from taxes and social contributions (ELT) and total environmental investments as \% in GDP (TEI). The methodology for the use of the cluster method targeted the ranking of countries, aiming to highlight the levels at which they are situated in order to assess the convergence of environmental protection.

Although at the European Union level there is a common framework for environmental policies (Rome 1957, Maastricht 1993, Amsterdam 1999, and Lisbon 2009) and a series of joint Environmental Action Programs, there are significant differences across groups of countries, and there are seven clusters identified for each of the two years analysed. 
The economic behaviour patterns of the $23 \mathrm{EU}$ countries are highlighted by the percentage value fluctuations recorded in each indicator introduced in the analysis but also in the clusters formed in both years analysed. The seven formed clusters face more or less significant changes, both in terms of values and structure.

Clusters $\mathrm{C} 1$ and $\mathrm{C} 3$ recorded the most significant fluctuation in the number of countries included in their composition. If in 2002, C1 is comprised of 7 countries, in 2011 there are 11 countries, of which 5 are found in both years: Belgium, France, Luxembourg, Austria, Finland indicating not only a high degree of homogeneity in terms of environmental policy but also in the implementation of a tax reform in this area, thus being possible benchmarks for the applicability of political regulations in other states, taking into account, naturally, the specific socio-economic context of each country. The countries that left C1 in 2002 are Italy and the UK. They will appear in 2011 in C4. Germany, Spain, Sweden, Slovakia components of the $\mathrm{C} 3$ cluster in 2002 will be found in the first cluster $\mathrm{C} 1$ in 2011.

In $\mathrm{C} 1$, as a whole, there were reductions in the average percentages by 0.2098 percentage points in environmental protection expenditure as \% in GDP, 0.4659 percentage points in shares of environmental and labour taxes in total tax revenues from taxes and social contributions, and 0.0409 percentage points in total environmental investments as $\%$ in GDP.

In the case of cluster $\mathrm{C} 3$, the situation is reversed in the sense that, although the number of component countries decreased in 2011 (7 countries: Germany, Estonia, Spain, Latvia, Romania, Slovakia, Sweden) compared to 2002 (2 countries: Estonia, Croatia) the environment protection funds increased, percentage average values being higher by 0.0507 percentage points for environmental protection expenditures as $\%$ in GDP, 2.3107 percentage points for the shares of environmental and labour taxes in total tax revenues from taxes and social contributions, 0.1586 percentage points for total environmental investments as\% in GDP.

The main feature of Clusters 2 and 6 is keeping a component country at the same level: Bulgaria for $\mathrm{C} 2$ and Malta for $\mathrm{C} 6$. Thus, in 2011, the funds for environmental expenditures in Bulgaria and Latvia compared to 2002 for Bulgaria and Poland experienced oscillations so that the average percentage value for environmental protection expenditure as $\%$ in GDP increased by 2.28 percentage points, for shares of environmental and labour taxes in total tax revenues from taxes and social contributions increased by 1.91, and for the total environmental investments as \% in GDP it decreased by 0.095 percentage points. A similar situation was also observed for C6 in the sense that for Malta and the Netherlands the components C6_2011 compared to Malta, Portugal in C6_2002, two increases and a decrease in the average value were noticed: by 0.63 percentage points in environmental protection expenditure as \% in GDP, by 0.025 percentage points in total environmental investments as \% in GDP, and 0.745 percentage points in shares of environmental and labour taxes in total tax revenues from taxes and social contributions.

Clusters 4 and 5 have only two component countries in both years analyzed. However, their composition changed both in 2011 and in 2002. Environmental funds in Italy, UK (C4_2011) compared with those in Croatia, Lithuania (C4_2011) are facing two 
increases in the average percentage values: by 0.795 percentage points in environmental protection expenditure as $\%$ in GDP, 0.1 percentage points in total environmental investments as \% in GDP, and with a decrease of 2,955 points in shares of environmental and labour taxes in total tax revenues from taxes and social contributions.

For cluster 5, with Hungary and Slovenia in 2002, and Lithuania and Romania in 2011, the distribution of the amounts allocated for environmental protection on the three categories analyzed is slightly different from the previous ones: with an increase in the average value of 0.63 percentage points in the environmental protection expenditure as \% in GDP and with two decreases - by 1.42 percentage points in the shares of environmental and labour taxes in total tax revenues from taxes and social contributions, and by 0.045 percentage points in total environmental investments as \% in GDP.

In C7_2011 (Poland, Slovenia) compared to C7_2011 (Netherlands), the average percentage values for each cluster recorded decreases for environmental protection expenditure as \% in GDP and share of environmental and labour taxes in total tax revenues from taxes and social contributions of 0.835 percentage points; and With 0.57 percentage points, respectively growth for total environmental investments as $\%$ in GDP by 0.125 percentage points.

At the level of all countries, the highest percentage for environmental protection, compared to the other two indicators, is for shares of environmental and labour taxes in total tax revenues from taxes and social contributions. Estonia is the country with the highest growth (35.58\% in 2011 compared to 2002), while Lithuania faces major problems given the decrease by $35.95 \%$ in the shares of environmental and labour taxes in total tax revenues from taxes and social contributions. This gap can also be explained by the fact that in most of the countries of the EU-15 sub-group the implementation of environmental policies has been achieved much earlier, and in some Central and Eastern European countries the harmonization of domestic policies with the EU strategy has been superficial.

\section{Limitations and Future Research Directions}

The non-inclusion in the study of the other 5 countries of the European Union (Cyprus, Denmark, Greece, Ireland, and Switzerland) was due to the lack of data regarding the variables studied at their level, and this omission is a limitation for this research. Future research will look at the analysis of constraints environmental policy faces in emerging economies in Central and Eastern Europe.

\section{Conflict of interests}

The authors declare no conflict of interest.

\section{References}

1. Andrei,J., Mieila, M., Popescu, G., Nica, E., \& Cristina, M. (2016). The impact and determinants of environmental taxation on economic growth communities in Romania. Energies, 9(11), 902.

2. Choi, S., \& Ng, A. (2011). Environmental and economic dimensions of sustainability and price effects on consumer responses. Journal of business ethics, 104(2), 269-282. 
3. Clark, J. (2017). Environmental Protection in Transition: Economic, Legal and Socio-Political Perspectives on Poland. Taylor \& Francis.

4. Costanza, R., Hart, M., Talberth, J., \& Posner, S. (2009). Beyond GDP: The need for new measures of progress. The pardee papers.

5. EUROSTAT (2017), available at: $h$ ttp://ec.europa.eu/eurostat/tgm/table.do?tab=table\&init=1\& plugin $=1 \&$ language $=$ en $\&$ pcode $=$ ten 00049

6. Gelder A., (2014). From Custer to Thermopylae: Last stand behavior in multi-stage contests. Games and Economic Behavior, 87(C), pp. 442-466.

7. Goodland, R. (1995). The concept of environmental sustainability. Annual review of ecology and systematics, 26(1), 1-24.

8. Hardisty, P.(2010). Environmental and economic sustainability. CRC Press, 2010.

9. Huang, B. N., Hwang, M. J., \& Yang, C. W. (2008). Causal relationship between energy consumption and GDP growth revisited: a dynamic panel data approach. Ecological economics, 67(1), 41-54.

10. Jugănaru, I.D. Jugănaru, M.(2011). Clusters in Romanian Tourism. Ovidius University Annals, Economic Sciences Series, XI(1):1107-1111

11. Labuschagne, C., Brent, A. C., \& Van Erck, R. P. (2005). Assessing the sustainability performances of industries. Journal of cleaner production, 13(4), 373-385.

12. Panayotou, T.(2016). Economic growth and the environment. The environment in anthropology, 140-148.).

13. Peeples, M. A. (2011) R Script for K-Means Cluster Analysis. [online]. Available: http://www. mattpeeples.net/kmeans.html. (July 13, 2016).

14. Rotariu, T., Bădescu, G., Culic, I., Mezei, E., \& Murean, C. (2006). Metode statistice aplicate în tiinele sociale Iai: Editura Polirom

15. Rotaru T. (ed.), Badescu G., Culic I., Mezei E. \& Murean C. ( 2006) Metode statistice aplicate în tiinele sociale, Ed. Polirom, Iai, pp. 272-303.

16. Sachs, W. (2015). Planet dialectics: Explorations in environment and development. Zed Books Ltd.

17. Spangenberg, J. H. (2005). Economic sustainability of the economy: concepts and indicators. International journal of sustainable development, 8(1-2), 47-64.

18. Zaharia, M., \& Gogonea, R. M. (2016). A Cluster Analysis of Industrial Production Indices in Some European Countries and Turkey. Economic Insights-Trends \& Challenges, 68(2).

19. Zaharia, M., Pătracu, A., Gogonea, M., Tănăsescu, A., \& Popescu, C. (2017). A cluster design on the influence of energy taxation in shaping the new EU-28 economic paradigm. Energies, $10(2), 257$.

20. Zilio, M., \& Recalde, M. (2011). GDP and environment pressure: the role of energy in Latin America and the Caribbean. Energy Policy, 39(12), 7941-7949. 